\title{
Industry Research and Professional Planning of Communication Technology
}

\author{
WangYueyue \\ Beijing Information Technology College \\ Beijing China \\ wangyy@bitc.edu.cn
}

\author{
Wan Dong \\ Beijing Information Technology College \\ Beijing China \\ wand@bitc.edu.cn
}

\begin{abstract}
Based on research and analysis of the communication industry, this paper analyzed the professional post and requirements of specific post of communication industry, also put forward the practical and feasible development plan. This paper can play guiding role in works of new major declaration and adaption of original communication technology in higher vocational college.
\end{abstract}

\section{Keywordss_Communication; Professional post; requirements}

\section{INTRODUCTION}

The chain structure of communication industry is shown in figure 1.The traditional operators takes important role in the chain. So analysis of telecom network, broadband and mobile communication business must focus on the operators, and then extended to various sub sectors. Communications equipment industry can be divided into system equipment, auxiliary equipment, system integration, optical fiber and cable, network planning and optimization, and operation and maintenance, terminal equipment, value-added services and so on. All of the industrial in this chain other related with the operators more or less.

\section{RESEARCH OF COMMUNICATIONS INDUSTRY}

\section{A. The upgraded $4 G$ of Mobile Communications}

Now, the upgraded cycle is significantly shortened in mobile communication technology with increased investment of human resource and capital. As mobile internet is the highlight of the $3 \mathrm{G}$ business, content, software and services developments are the mainstream of 4G-LTE era. As shown in Figure 2, the global LTE infrastructure market will increase from \$15 in 2011 to $\$ 211$ in 2016, with 55.8\% compound growth rate. The development of LTE has deployed some new growth engine for the communication industry.

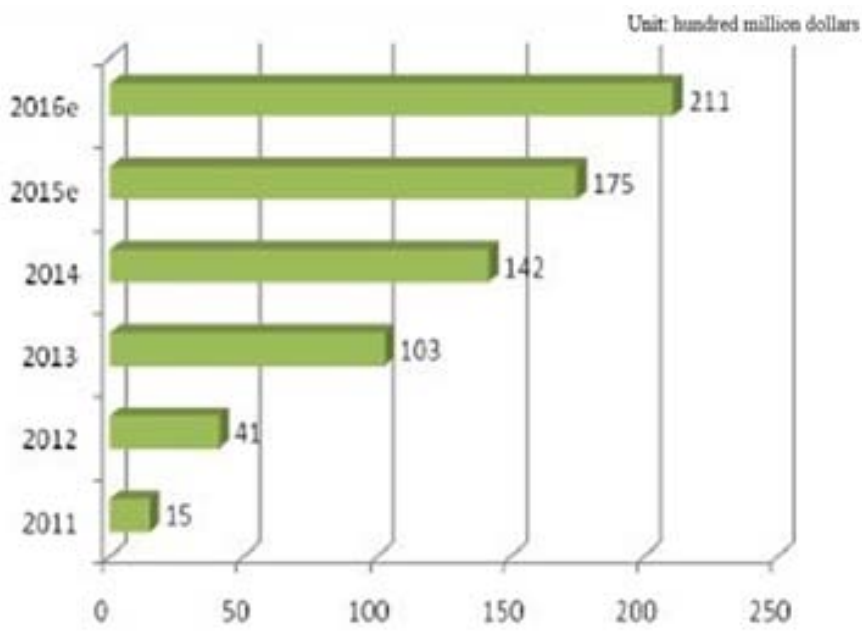

Fig.2 Market Scale and Forecast of Global LTE Equipment

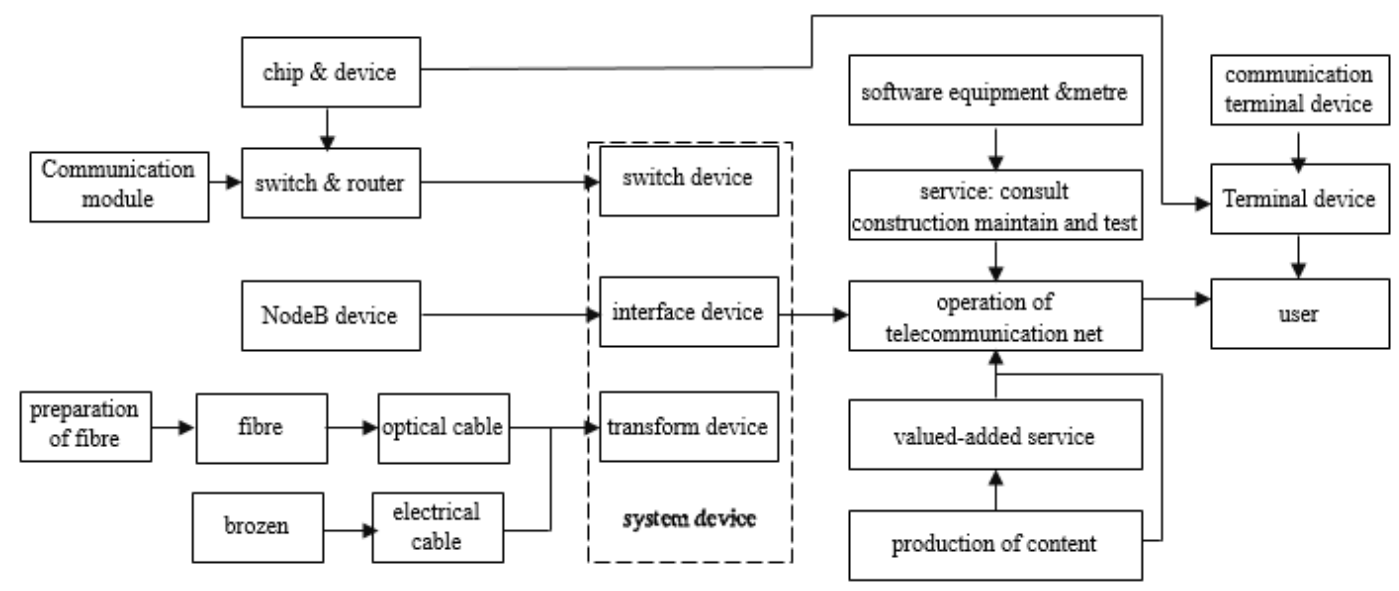

Fig.1 The industrial Chain of Communication Industry 


\section{B. Steady Development of Cable Broadband}

Cable broadband is irreplaceable with its exclusive, safe and reliable characteristics. And which has made it to be an important part in the future of the development of data services. Some research shows that, there could an increase of $1.4 \%$ of the GDP as shown in Figure 3. Also, the research data of Bruce Institute shows that if the rate he broadband penetration increase $1 \%$, the employment rate will increase by $0.2-0.3 \%$. And the high return brought by investment of broadband has benefited a lot for each government.

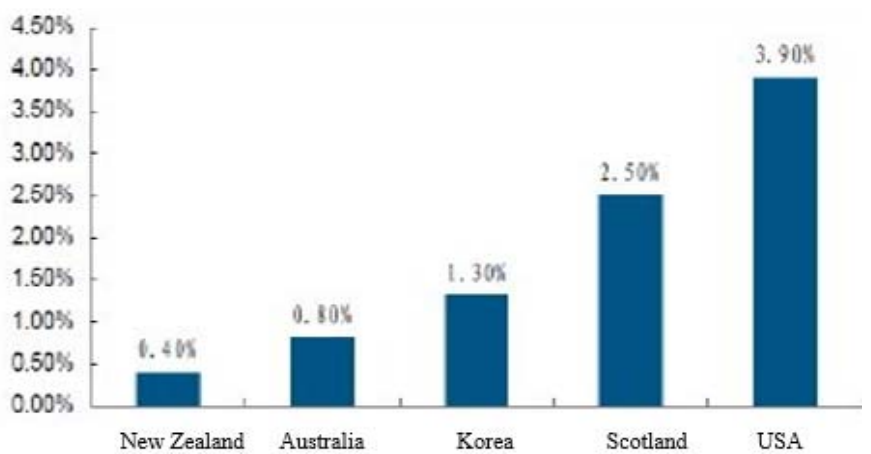

Fig.3 The GDP Growth promoted by Broadband in Recent Five Years

\section{Triple paly}

Triple play means the technical integration of TV network, telecommunication network and Internet, which provide a comprehensive multimedia communications services, including voice, data, images, etc. For which IP is the core technology, as shown in Figure 4. The integrated net is not only flexible and cheap but also has much better reliability and stability than the traditional communication net. Triple play will drive the development of the whole communication chain including content providers, service providers, operators, communications equipment manufacturers and so on.

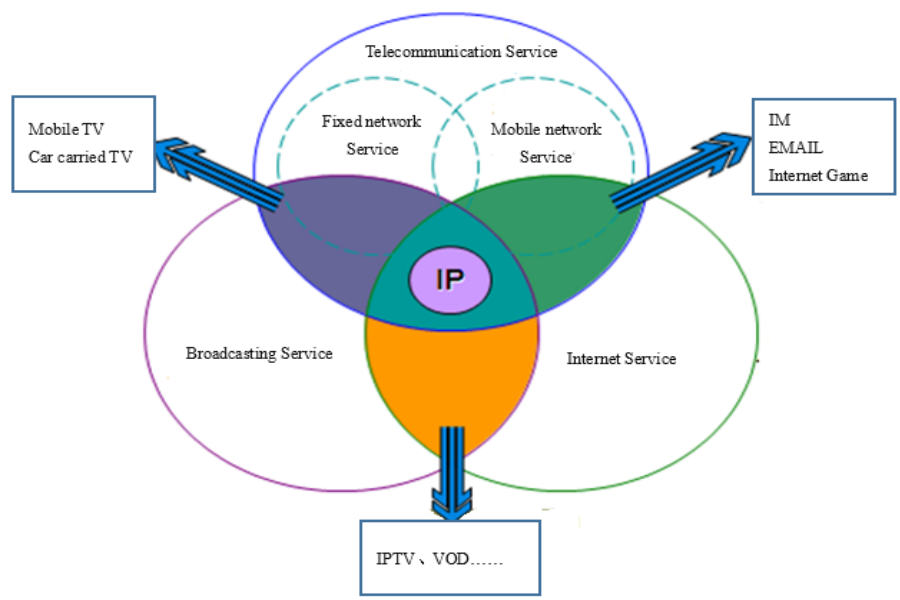

Fig.4 Diagram of triple integration

\section{Combination of Things and Mobile Networks}

At present, China Mobile is developing the application of the Internet of things which can run on the mobile network vigorously. The integration system architecture of Internet of things and mobile network is shown in Figure 5. All terminal equipment of Internet of things need to connect with mobile network and business platform with a M2M platform. Mobile networks can be integrated further to form a large network to help to develop the use of Internet of things.

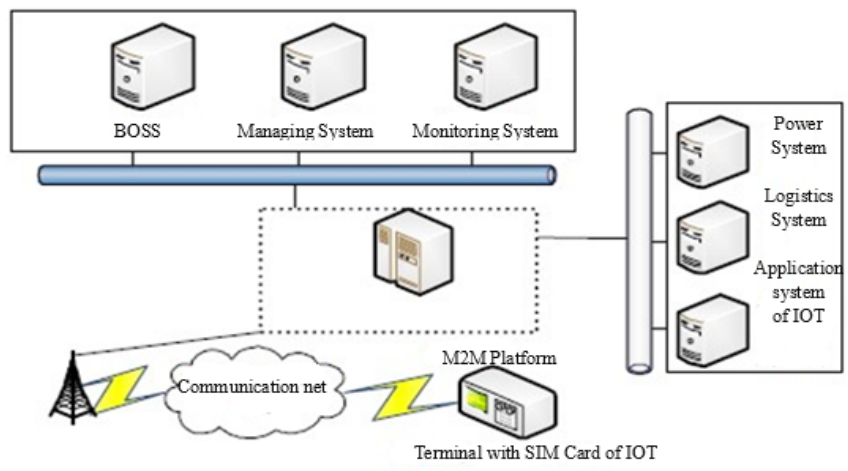

Fig.5 Integration system architecture of Internet of things and mobile network

\section{POST ANALYSIS OF COMUNICATION}

Communications major has a broad prospects for development, and extensive employment direction including software and hardware.

TABLE I. COMMUNICATION POST CLASSIFY

\begin{tabular}{|c|c|c|}
\hline \multicolumn{2}{|c|}{ Post Category } & Post Name \\
\hline \multirow{3}{*}{\multicolumn{2}{|c|}{ Plan Design }} & Network planning engineer \\
\hline & & $\begin{array}{l}\text { Installation design engineer } \\
\text { nation }\end{array}$ \\
\hline & & Field survey and budget \\
\hline \multirow{14}{*}{$\begin{array}{l}\text { Technic } \\
\text { service }\end{array}$} & \multirow{3}{*}{$\begin{array}{c}\text { Installation } \\
\text { Test }\end{array}$} & Station installation and adjustment test engineer \\
\hline & & Base station controller installation engineer \\
\hline & & Core network installation engineer \\
\hline & \multirow{4}{*}{$\begin{array}{c}\text { Operation } \\
\text { Maintenance }\end{array}$} & Base station maintenance engineer \\
\hline & & Base station controller Maintenance engineer \\
\hline & & Core network maintenance engineer \\
\hline & & Transmission network maintenance engineer \\
\hline & \multirow{5}{*}{$\begin{array}{c}\text { Optimization } \\
\text { Of network }\end{array}$} & Road eest engineer \\
\hline & & Data analysis engineer \\
\hline & & Wireless optimization engineer \\
\hline & & Performance statistical analysis engineer \\
\hline & & Indoor distribution engineer \\
\hline & \multirow{2}{*}{ Service } & Technical support for sales and sales \\
\hline & & Business management \\
\hline \multirow{4}{*}{\multicolumn{2}{|c|}{$\begin{array}{c}\text { Marketing } \\
\text { Sales }\end{array}$}} & Account manager \\
\hline & & Marketing manager \\
\hline & & Business promotion \\
\hline & & Product sales \\
\hline \multirow{4}{*}{\multicolumn{2}{|c|}{$\begin{array}{c}\text { Research } \\
\text { Development }\end{array}$}} & Test engineer \\
\hline & & Software development \\
\hline & & Hardware development \\
\hline & & System architecture engineer \\
\hline
\end{tabular}


Graduates can be engaged in advanced specialized work such as research, design and development of product and protocol in research institutes, high-tech development companies, design institutes and universities. Also, they can be engaged in the production, manufacturing, technical support, sales service and any other work of communication industry. The classified post is shown is Table1.

\section{COMmunication Major Scheme}

\section{A. Training Aim}

Aiming at communication equipment manufacturing, communications network operating and any other related posts, Communication professional training skilled personals with nice moral character, good health, good mental quality, and solid knowledge of communication network and digital communication technology, who mastered the skill of communication network protocol and the skill of communication network construct and maintenance, who can install and debug of transform and switch equipment, open and maintain communication net and test the terminal equipment.

\section{B. Basic Quality Requirements}

1) nice moral sense

2) nice physical and mental health

3) nice information processing capacity

4) nice problem analysis and solving skills

5) nice communication and cooperation

6) nice safety and environmental awareness

7) nice innovation capability

8) can comply with the rules and regulations

\section{Professional Capacity Requirements}

1) can read and understand the communication equipment circuit diagram, the assembly plan, and can check circuit according to the principle diagram;

2) can computer and software to handle data and words, can read the relevant foreign language information.
3) can use common communication instruments and equipment;

4) can efficiently install and configure the digital switching equipment;

5) can efficiently install and configure optical transmission equipment;

6) can construct and maintain a data network;

7) can debug and maintain the access network;

8) can install mobile base stations, manage core network and optimize network;

9) can design, implement and manage communication project.

\section{Core Curriculum}

1) analysis and testing of digital communication systems

2) operation and maintenance of program controlled switching equipment

3) construction and maintenance of optical transmission network

4) operation and maintenance of data communication network

5) wireless broadband access technology

6) construction of mobile base station and network optimization

7) management of communication engineering project

\section{E. Requirement of Teacher}

1) Education Level: Master's degree or above;

2) Major: communication, electronic information and other related majors;

3) Technical Title: deputy senior or above;

4) Practical Ability: with the practice experience in communication industry enterprise for more than half a year, with the high qualification certification of communication or electronic information.

5) Work Attitude: serious and ethics professional.

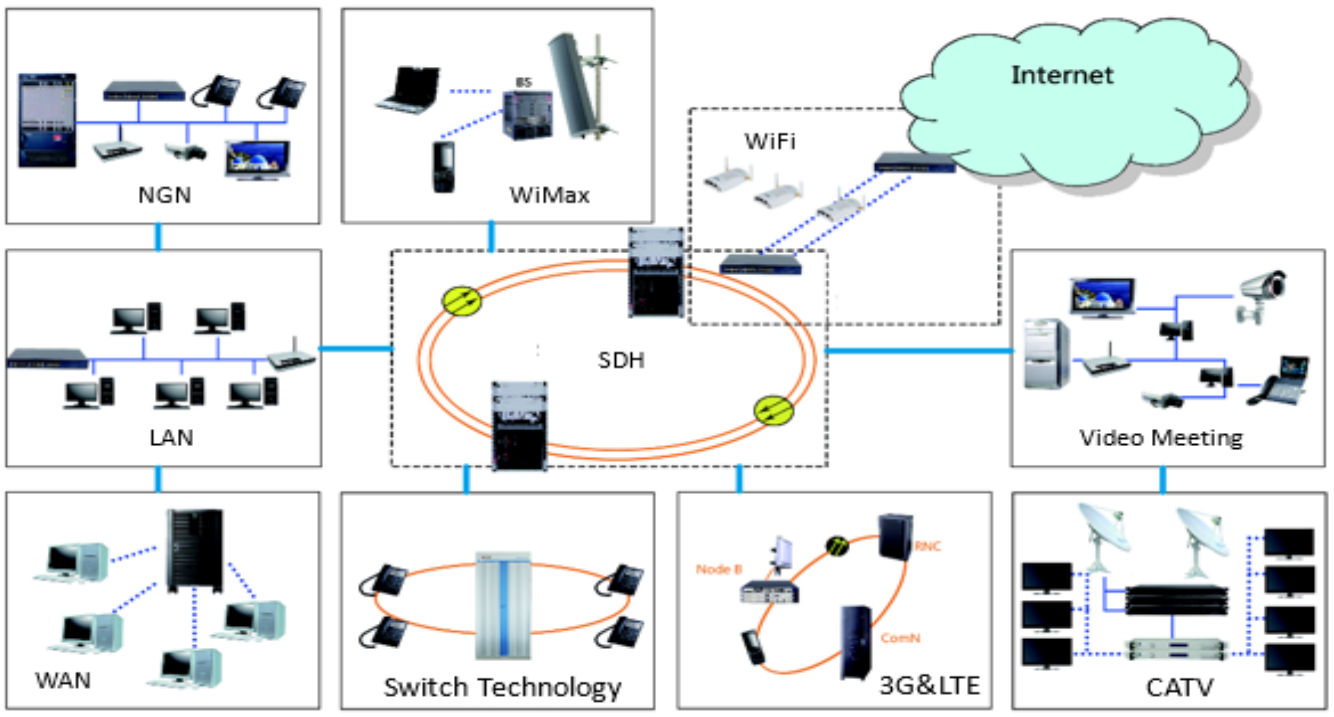

Fig.6 Training rooms of communication major 


\section{F. Requirements of Training room}

Requirements of Training room is shown as figure 6. There should be several rooms detailed as following:
1) NGN Training Room
2) WiFi\&WiMax Training Room
3) LAN\&WAN Training Room
4) Switch Technology Training Room
5) 3G\&LTE Training Room
6) CATV Training Room

\section{CONCLUSION}

From the analysis of communication industry chain, this paper introduces the new development of mobile communication, cable broadband, triple play and Internet of things. The paper analyzes the professional post and requirements of these post in communication technology based on the research of communication industry. And proposed feasible major development plan which includes training aim, quality, ability, curriculum setting, teacher requirements and configuration of training room and so on. So it can play guided role in works of new major declaration and adaption of original communication technology in higher vocational college.

\section{REFERENCES}

[1] Yao Hongyuan. Present situation and Prospect of optical fiber communication technology in China.China New Communication,2014.

[2] Fan Caiyuan. The development and application of computer communication technology. Communication of Information,2014

[3] Fan Xuemei.Research and summary of the development of the Internet of things technology. Computer measurement and control.2014.

[4] Xing Maozhu.Development of ultra wideband wireless communication technology. Technology and Enterprize, 2013. 